\title{
Diagnosis of infantile neuroaxonal dystrophy by conjunctival biopsy
}

\author{
M. L. A R SÉ N I O-NUNES ${ }^{1}$ A N D F. GOU T I ÈRES \\ From U 154 INSERM, Hôpital St Vincent de Paul, Paris, France
}

SUMMARY Conjunctival biopsy and ultrastructural examination of conjunctival nerves, showing the presence of spheroids within axons, led to the confirmation of the diagnosis of infantile neuroaxonal dystrophy in two children with progressive mental deterioration. Conjunctival biopsy, which is simple to perform, even in young children, and does not require general anaesthesia or admission to hospital, is presented as a reliable and very convenient technique for the diagnosis of infantile neuroaxonal dystrophy.

The diagnosis of infantile neuroaxonal dystrophy (Seitelberger's disease) has been established, up to the present time, mainly by the characteristic pathological features-ballooned axons containing collections of packed membranous and tubular structures-observed in histological and ultrastructural studies of brain and peripheral nerve biopsy samples (Seitelberger, 1952; Lyon and Sée, 1963; Herman et al., 1969; Duncan et al., 1970; Butzer et al., 1975; Shimono et al., 1976). Muscle biopsy with electron microscopic examination of intramuscular nerves and motor endplates has also been shown by Berard-Badier et al. (1971), Sengel and Stoebner (1972), and Martin and Martin (1972) to be a useful method of diagnosis in infantile neuroaxonal dystrophy. The involvement of peripheral nerve suggested to us the possible value of conjunctival biopsy and ultrastructural study of conjunctival nerves in the diagnosis of this condition. This led to the confirmation of the diagnosis of infantile neuroaxonal dystrophy in two children with progressive mental deterioration.

\section{Case reports}

\section{CASE 1}

A girl, born in April 1974, walked at 12 months and was normal until 16 months of age. She then began to regress, stopped walking, and became very floppy. When first examined at 33 months she

'Chargé de recherche a l'INSERM.

Address for reprint requests: Dr M. L. Arsénio-Nunes, U 154 Inserm, Hôpital St Vincent de Paul, 74 Avenue Denfert-Rochereau, 75674 Paris Cedex 14, France.

Accepted 29 January 1978 lay motionless on her back, could not support her head, and exhibited severe generalised hypotonia with bilateral pyramidal tract signs, increased tendon jerks, and optic atrophy. The CSF was normal. The EEG disclosed fast high voltage activity largely replacing background activity. Conjunctival biopsy was performed in January 1977.

\section{CASE 2}

A boy, the second child of healthy and unrelated parents, developed normally until 11 months of age. He then stopped making progress and began to regress in development. At 22 months he appeared severely retarded mentally and extremely hypotonic with increased tendon jerks and bilateral extensor plantar responses. The fundi exhibited optic atrophy. The CSF was normal. Electromyography of the quadriceps, deltoids, and tibialis anterior muscles displayed tracings with high amplitude potentials interpreted as typical evidence of a neurogenic lesion; motor nerve conduction velocity was normal. Conjunctival biopsy was performed at age 24 months.

\section{Methods}

Conjunctival biopsies were performed under topical anaesthesia induced by oxybuprocaine chlorure (Novesine) $0.40 \%$. In both cases a single sample $2 \mathrm{~mm}$ long and $1.5 \mathrm{~mm}$ wide was taken from the upper bulbar conjunctiva. The samples were fixed immediately in $3 \%$ phosphate buffered glutaraldehyde (two hours), cut in thin slices, washed in $5 \%$ phosphate buffered glucose, and 
post-fixed in $2 \%$ phosphate buffered osmium tetroxide (one hour at $4^{\circ} \mathrm{C}$ ). After washing, the slices were in-block stained with uranyl acetate (90 minutes), dehydrated in a graded series of alcohols, and embedded in Araldite. Thick sections
$(1.0 \mu \mathrm{m})$ stained with toluidine blue were observed under the light microscope to select the regions containing nerve fibres. Ultra-thin sections were stained with uranyl acetate and lead citrate and examined in a Siemens 101 electron microscope.

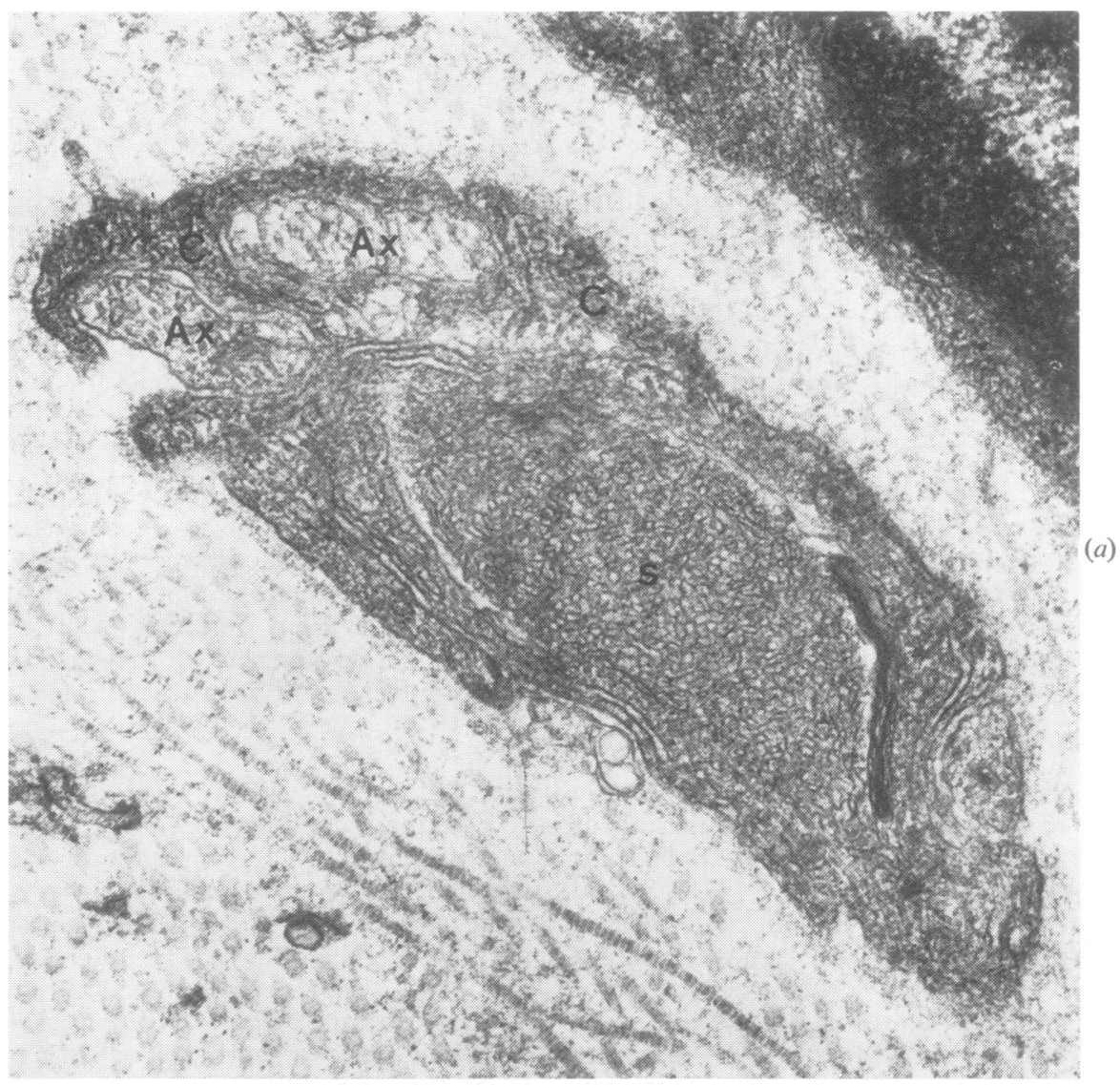

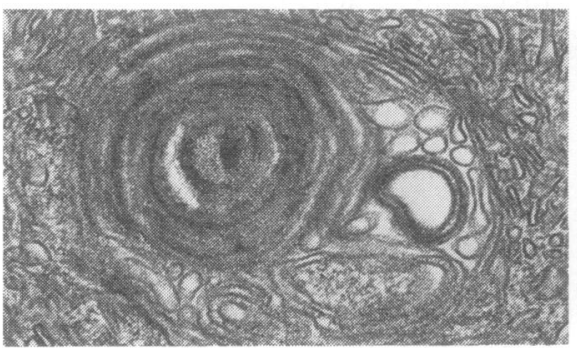

(b)

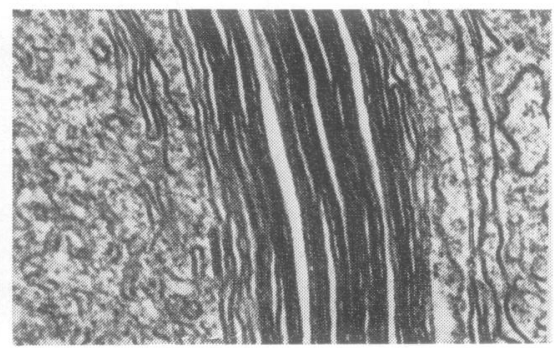

(c)

Fig. 1 Case 1: (a) unmyelinated axon almost completely filled by a large spheroid (s). Other axons $(A x)$ devoid of spheroids are surrounded by the same Schwann cell $(C)$, $\times 45$ 000; $(b)$ and $(c)$ details of the structure of some spheroids-(b) concentric arrays of membranous structures, $\times 46500$, and $(c)$ bundle of parallel membranes, $\times 70000$. 


\section{Results}

CASE 1

In every conjunctival nerve observed (15) there were three to five abnormal fibres (myelinated and unmyelinated) for every seven to nine normal fibres. The myelin sheaths of altered fibres were generally thinner than usual, and some lamellae were separated by slight oedema and showed honeycomb figures. The axons of these fibres had densely packed filaments and dilated smooth endoplasmic reticulum. However, typical spheroids were only observed in unmyelinated axons. These spheroids consisted chiefly of aggregates of tubular and membranous structures disposed in a compact network which filled the axons almost completely (Fig. 1a). Bundles of parallel membranes arranged in longitudinal or concentric patterns (Fig. 1b, c)

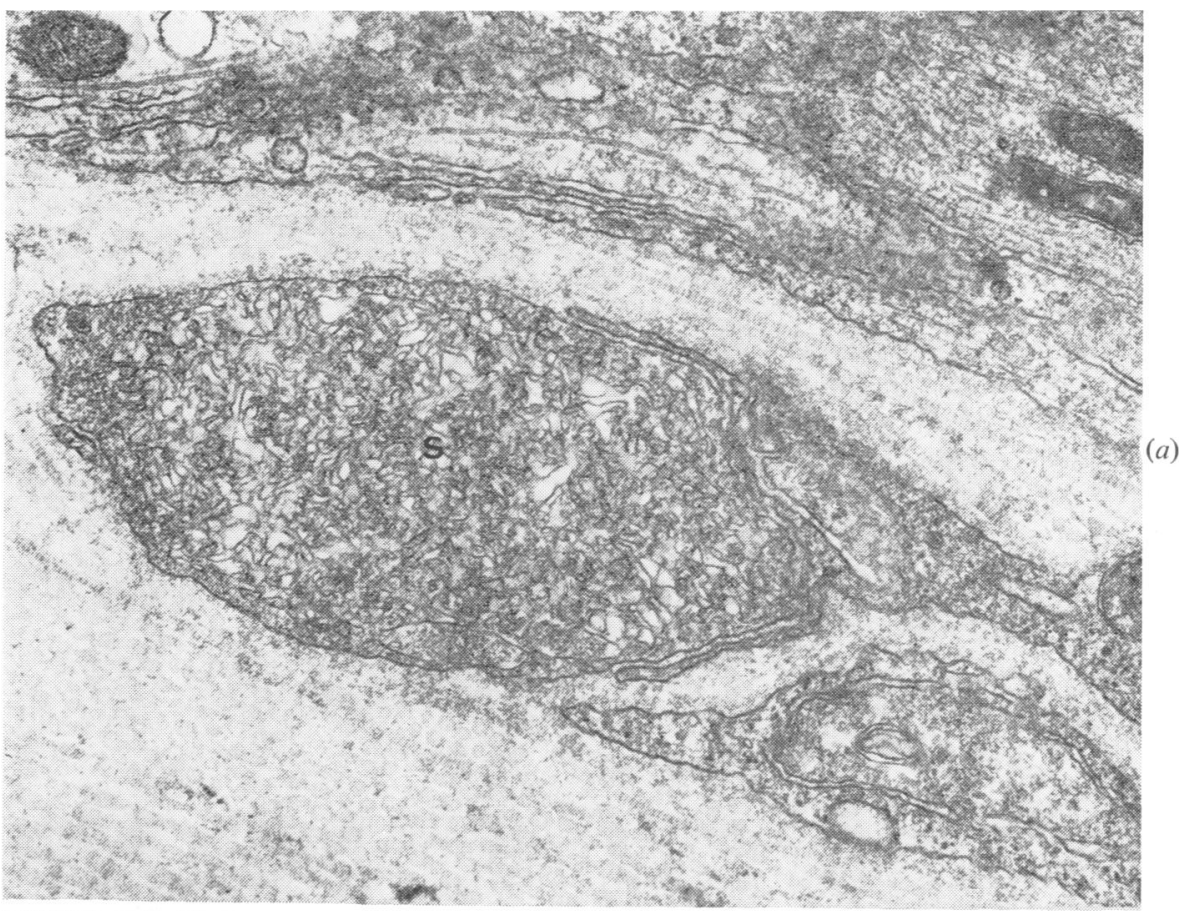

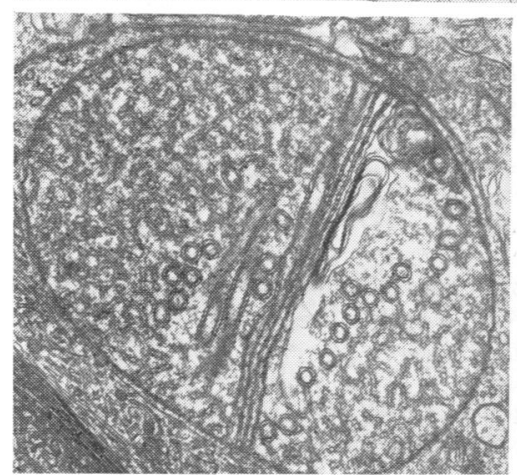

(b)

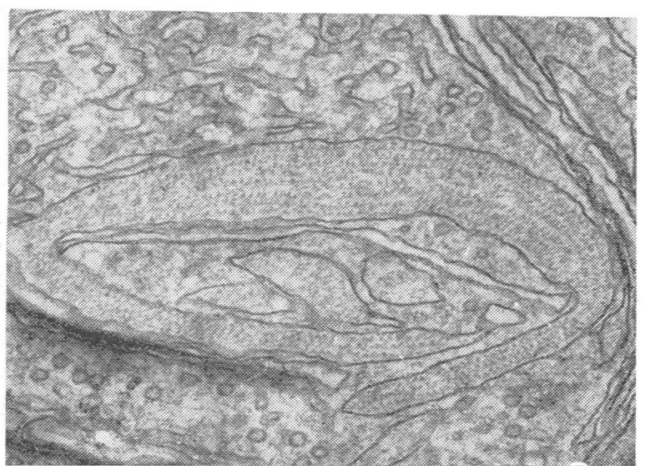

(c)

Fig. 2 Case 2: (a) spheroid (s) within an unmyelinated axon; on the left the structure of the axon is still identified, $\times 32$ 000; (b)mitochondrion with circular cristae lying close to a spheroid, $\times 24$ 500; (c) axon showing a structure resembling a Hirano body, and tubular structures of a spheroid, $\times 82500$. 
lay frequently within the spheroids. Abnormal mitochondria, containing crystalline-like inclusions or having circular arrangement of their cristae, were detected in occasional axons. A single filamentous inclusion similar to Hirano bodies was also observed in an enlarged axon.

The Schwann cells did not exhibit significant changes.

\section{CASE 2}

The percentage of altered fibres in each nerve was identical to that found in case 1. Qualitative changes of myelinated axons were also similar. The spheroids, which were also found only in unmyelinated axons, had a more polymorphic structure. The collections of randomly disposed membranous and tubular structures were again the main feature (Fig. 2). However, within the spheroids abnormal mitochondria with circular cristae (Fig. 2b) and numerous bundles of collapsed membranes were frequently seen. In several unmyelinated axons filamentous bodies made up of wire loops of a fibrillary material disposed in parallel arrays were found. These structures resembling Hirano bodies were observed either within spheroids (Fig. 2c) or in sections of axons where spheroids did not occur.

The structure of the Schwann cells was unremarkable.

\section{Discussion}

In both cases the electron microscopic study of conjunctival biopsy specimens showed the presence of typical spheroids in several unmyelinated axons. Their structure was identical to that described in the spheroids of the central nervous system and the peripheral nerves.

The collections of the packed membranous or tubular structures were easily identified in the conjunctival nerves. The nature of these structures is unknown, although they have been considered to be the result of hyperplasia of the smooth endoplasmic reticulum (Lampert, 1967; Toga et al., 1970; Jellinger and Jiràsek, 1971) or the consequence of an overproduction of a macromolecular substance related to neurotransmitters and their receptors (Liu et al., 1974).

The abnormal mitochondria and the structures resembling Hirano bodies often reported in brain biopsy samples of infantile neuroaxonal dystrophy (Toga et al., 1970; Berard-Badier et al., 1971; Yagishita and Kimura, 1974, 1975), were also found within the axons of the conjunctiva in the present two cases.

These results and the fact that conjunctival bi- opsy is simple to perform, even in young children, and does not require general anaesthesia or admission to hospital, indicate that this technique is a reliable and very convenient method in the diagnosis of infantile neuroaxonal dystrophy.

\section{References}

Berard-Badier, M., Gambarelli, D., Pinsard, N., Hassoun, J., and Toga, M. (1971). Infantile neuroaxonal dystrophy or Seitelberger's disease. II Peripheral nerve involvement: electron microscopic study in one case. Acta Neuropathologica (Berlin), Supplement V, 30-39.

Butzer, J. F., Schochet, S. S., and Bell, W. E. (1975). Infantile neuroaxonal dystrophy. An electron microscopic study of a case clinically resembling neuronal ceroid-lipofuscinosis. Acta Neuropathologica (Berlin), 31, 35-43.

Duncan, C., Strub, R., McGarry, P., and Duncan, D. (1970). Peripheral nerve biopsy as an aid to diagnosis in infantile neuroaxonal dystrophy. Neurology (Minneapolis), 20, 1024-1032.

Herman, M. M., Huttenlocher, P. R., and Bensch, K. G. (1969). Electron microscopic observations in infantile neuroaxonal dystrophy. Report of a cortical biopsy and review of the recent literature. Archives of Neurology (Chicago), 20, 19-34.

Jellinger, K., and Jiràsek, A. (1971). Neuroaxonal dystrophy in man: character and natural history. Acta Neuropathologica (Berlin), Supplement V, 3-16.

Lampert, P. W. (1967). A comparative electron microscopic study of reactive, degenerating, regenerating and dystrophic axons. Journal of Neuropathology and Experimental Neurology, 26, 345-368.

Liu, H. M., Larson, M., and Mizuno, Y. (1974). An analysis of the ultrastructural findings in infantile neuroaxonal dystrophy (Seitelberger's disease). Acta Neuropathologica (Berlin), 27, 201-213.

Lyon, G., and Sée, G. (1963). La dégénérescence neuro-axonale infantile (maladie de Seitelberger). Etude anatomique d'une observation. Revue Neurologique, 109, 133-155.

Martin, J. J., and Martin, L. (1972). Infantile neuroaxonal dystrophy: ultrastructural study of the peripheral nerves and of the motor end plates. European Neurology, 8, 239-250.

Seitelberger, F. (1952). Eine unbekaunte Form von infantiler Lipoid-speicher-Krankheit des Gehirns. Proceedings of the 1st Congress of Neuropathology, Rome, Vol. 3, pp. 323-333. Rosenberg and Sellier: Turin.

Sengel, A., and Stoebner, P. (1972). Intérêt de la biopsie neuro-musculaire dans le diagnostic de la dystrophie neuro-axonale infantile. Etude ultrastructurale de 3 cas dont 2 familiaux. Acta Neuropathologica (Berlin), 21, 109-116.

Shimono, M., Ohta, M., Asada, M., and Kuroiwa, Y. (1976). Infantile neuroaxonal dystrophy. Ultrastructural study of peripheral nerve. Acta Neuropathologica (Berlin), 36, 71-79. 
Toga, M., Berard-Badier, M., and Gambarelli-Dubois, D. (1970). La dystrophie neuro-axonale infantile ou maladie de Seitelberger. Etude clinique, histologique et ultrastructurale de deux observations. Acta Neuropathologica (Berlin), 15, 327-350.

Yagishita, S., and Kimura, S. (1974). Infantile neuroaxonal dystrophy (Seitelberger's disease). Histologi- cal and electron microscopical study of two cases. Acta Neuropathologica (Berlin), 29, 115-126.

Yagishita, S., and Kimura, S. (1975). Infantile neuroaxonal dystrophy (Seitelberger's disease). A light and ultrastructural study. Acta Neuropathologica (Berlin), 31, 191-200. 